\title{
Feed Conversion Efficiency (FCE) in Relation to Reproductive Performance of Sow
}

\author{
Kandarpa Boruah $^{1 *}$, Jitendra Saharia ${ }^{1}$, Simson Soren ${ }^{2}$, Karuna Saikia ${ }^{2}$, \\ Arindam Chakraborty ${ }^{2}$ and Mridusmrita Burhagohain ${ }^{2}$
}
${ }^{1}$ Livestock Production and Management, College of Veterinary Science, Assam Agricultural University, Khanapara-781022, India
${ }^{2}$ Lakhimpur College of Veterinary Science, Assam Agricultural University, North Lakhimpur, Joyhing-787051, India

*Corresponding author

\author{
A B S T R A C T
}

\begin{tabular}{|l|}
\hline Ke y w o r d s \\
Feed conversion \\
efficiency, Sow, \\
Reproductive \\
performances, \\
Northeastern region
\end{tabular}

\section{Keywords}

Northeastern region

Article Info

Accepted:

December 2017

Available Online:

\section{Introduction}

The increasing demand for animal source food in the northeastern region (NER) in India suggesting well intervention to pig production. As per latest $19^{\text {th }}$ Livestock Census, 2012 Govt. of India and Basic Animal Husbandry and Fisheries Statistics, Govt. of India (2014), the pig population of the country is 10.29 million which share around $2.01 \%$ of total livestock population. NER is having 3.91
The northeastern region (NER) possessing the highest population of pigs in India. The livelihood of many communities in NER comes from piggery. The demand for meat and piggery production is challenged due to increase in the price of grain and feed for animal consumption. The Feed conversion efficiency (FCE) is gaining pre-eminence for selection of pigs in piggery. Pigs having better FCE are profitable to farmers, as they gain weight from less input. However, the correlation of FCE with reproductive performances of pigs is very limited. Therefore, the present study was designed to study the relationship between different FCE with reproductive performances of pigs. The correlation study revealed that the Pigs having medium or average FCE showed a positive correlation with reproductive performances viz. litter weight at birth $(0.315)$, litter size at birth $(0.253)$, live born piglets (0.289), litter weight at weaning $(0.253)$ and litter size at weaning $(0.381)$. Pigs having FCE below average and over did not show a positive correlation with reproductive performance. It can be concluded that FCE should be correlated with reproductive performance of pig for selecting the animals for the future stock. 
having good feed conversion efficiency. Therefore, feed conversion efficiency (FCE) is an important tool for the parameter to measure the economic viability of a commercial farm. It helps the producer to determine the production costs and recognized as a prominent marker of profitability for pork producers (Edwards et al., 1989).

Because the feed cost alone contributes more than $70 \%$ of the total cost of pork production. So, it is one of the major goals to improve the FCE in pork production (Henry, 1992).

The farm economy not only necessary for good FCE but also depends on the reproductive performance of the animals. The poor reproductive performance may not able to maintain the productivity of the farm. The present study was to correlate different FCE with reproductive performance of pig in Assam.

\section{Materials and Methods}

\section{Selection of animals and management}

Twenty pregnant Hampshire sows were selected from thirty sow unit, Department of Livestock Production and Management, College of Veterinary Science, Assam Agricultural University, Khanapara of second and third parity for this experiment and divided into groups viz., group-I (sow having FCE 4 - 4.9, $n=4$ ), group- II (sow having FCE $5.0-5.9, n=8$ ) and group - III (sow having FCE $6.0-6.9, n=8$ ). They were fed similar feeding standard ration as shown in table 1 to all the groups.

Feed requirements of the sows were estimated by conducting a pilot trial for a period of 10 days prior to the commencement of the actual experiment and from the feed offered and leftover, the feed consumption was worked out.

\section{Feed conversion efficiency (FCE)}

The residues of the feed offered daily were collected in the next morning and amounts were recorded. The Voluntary Feed Intake (by taking residues into account) was recorded daily. When no residues were left in the feeding trough, the feed allowances were increased on the following day. The daily voluntary feed intake by individual sows was recorded throughout the entire experimental period and calculated fortnightly for both control and treatment groups. Fortnightly body weight gains of pregnant sow were recorded for FCE calculation. Feed conversion efficiency was calculated by dividing total quantity of feed consumed (kg) with body weight gain $(\mathrm{kg})$.

\section{Reproductive parameters}

Litter weight at birth was recorded as the total body weight of all piglets born alive to a dam at each farrowing. Litter size was also recorded at birth. The total numbers of live piglet were recorded in each of the sows farrowed. The body weights of all piglets were recorded in the morning before feeding during the entire period of the experiment at fortnightly intervals with the help of $50 \mathrm{~kg}$ capacity spring balance.

The body weights were recorded in kilogram nearest to $200 \mathrm{~g}$. Litter size at weaning was also recorded up to 56 days of age at fortnightly interval. The Service period was calculated from the difference between the date of farrowing and date of subsequent fertile service and was expressed in days.

\section{Statistical analysis}

The statistical analysis was carried out by using Prism 5 software. Person correlation coefficient was done between the reproductive performances of animals having different 
FCE. The figures were drawn using Prism 5 software.

\section{Results and Discussion}

Pigs having FCE average "5" showed a positive correlation with litter weight at birth (0.315), litter size at birth (0.253), litter size at weaning (0.381), live born piglet (0.289), litter weight at weaning (0.253) and litter size at weaning $(0.381)$ (Figure 1). Service period did not show a positive correlation with FCE. However, pigs having FCE average " 4 " and "6"Showed a negative correlation with litter size at weaning (-0.832 and -0.777), litter weight at birth $(-0.259$ and 0.030$)$, litter size at weaning (-0.697 and -0.725$)$ and live born piglet $(-0.697$ and 0.025$)$.

Sustainability of piggery production is essential in NER that might be one of the strategies for eradicating poverty. The livelihood of many communities of northeastern states comes from piggery. The demand for production depends on input i.e. more production from less input. Therefore, the feed-conversion ratio is an important determinant of profitability for swine producers (Edwards et al., 1989). Because feed costs represent approximately two-thirds of the total cost of pork production, small increments in the feed-conversion ratio can have a major impact on the profitability of an operation. Therefore, improving the feedconversion ratio is a major goal in pork production (Henry, 1992). Genetic selection (which has concentrated on increased growth and reduced fat) is an important factor that has had an impact on improving the feedconversion ratio (Henry, 1992). Diet and use of antibiotics can influence the feedconversion ratio in pigs (Henry, 1992; Tribble et al., 1956). Lopez et al., (1991) have found the inferior feed conversion ratios in coldstressed pigs. Feed conversion efficiency showed poor performance in overcrowded pigs (Brumm and Miller, 1996). It has been observed that diseases can impact the feed conversion ratio in pigs (Muirhead, 1989; Straw et al., 1989). However, the present study showed the impact on the reproductive performance of pigs when the FCE was less and very high, but profitable when the FCE is medium. The study indicates that very less FCE may not be effective for reproductive performances and very high FCE may not be economic as well as poor reproductive performances. Pork producers and those who serve their needs require a better understanding of factors that can influence the feed-conversion ratio in pigs as well as reproductive performances.

\section{Selection of animals and management}

\begin{tabular}{|l|c|c|}
\hline \multirow{2}{*}{ Ingredients } & \multicolumn{2}{|c|}{ Parts (\%) } \\
\hline Maine & Starter & $\begin{array}{c}\text { Gestation and } \\
\text { lactation }\end{array}$ \\
\hline Wheat bran & 50 & 35 \\
\hline Rice polish & 22 & 25 \\
\hline Ground nut cake & - & 13 \\
\hline Fish meal & 20 & 19 \\
\hline Mineral mixture & 5 & 5 \\
\hline Salt & 2.5 & 2.5 \\
\hline Total & 0.5 & 0.5 \\
\hline
\end{tabular}

N.B: Vitamin A, D, E, K was added @ 200gm/100 kg ration. 
Fig.1 The correlation coefficient of animal having FCE 5.0 to 5.9 with their reproductive performances
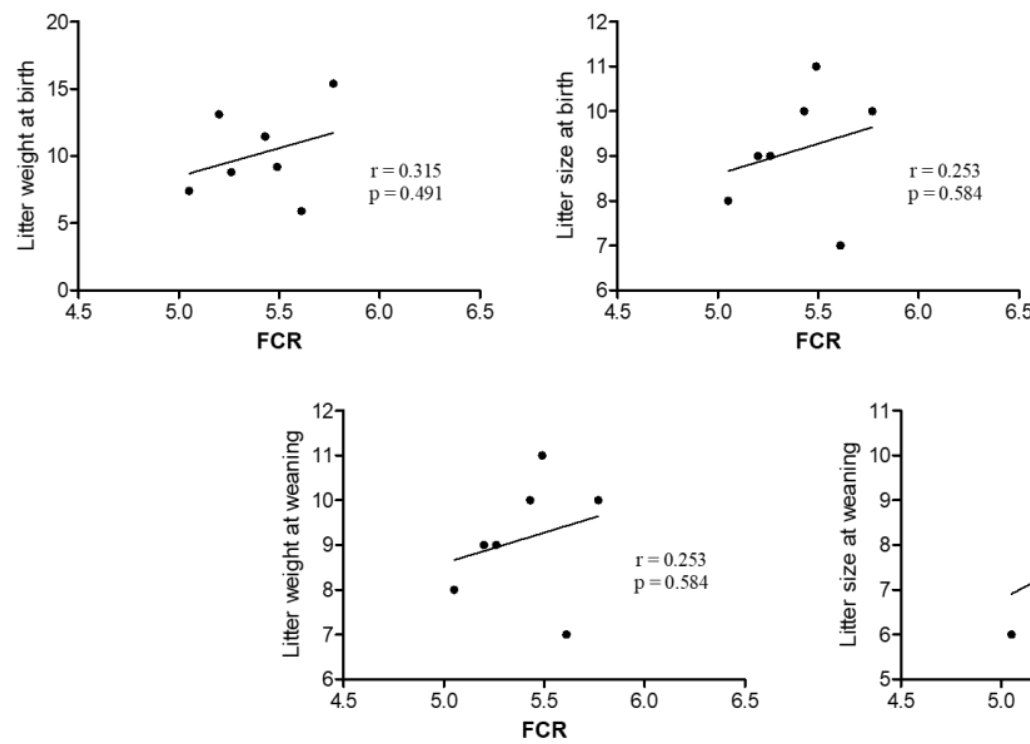

The FCE is gaining preference in the recent year. The objective of this correlation study was to examine different FCE with relation to their reproductive performances. The FCE may differ due to many factors viz., environment, feed additives, diseases and quality of feed. The study in the present finding indicates that the reproductive performances may not be accepted when FCE is too less or too high, the pig having medium FCE might be better for the economic benefit to the farm.

\section{References}

Brumm, M.C., and Miller, P.S. 1996. Response of pigs to space allocation and diets varying in nutrient density. J. Anim. Sci. 74, 2730-2737.

Edwards, W.M., G.T. Van der Sluis and Stevermer, E.J. 1989. Determinants of profitability in farrow-to-finish swine production. North Central J. Agr. Econ. 11, 17- 25 .

Govt. of India, New Delhi 2014. Basic Animal Husbandry and Fisheries
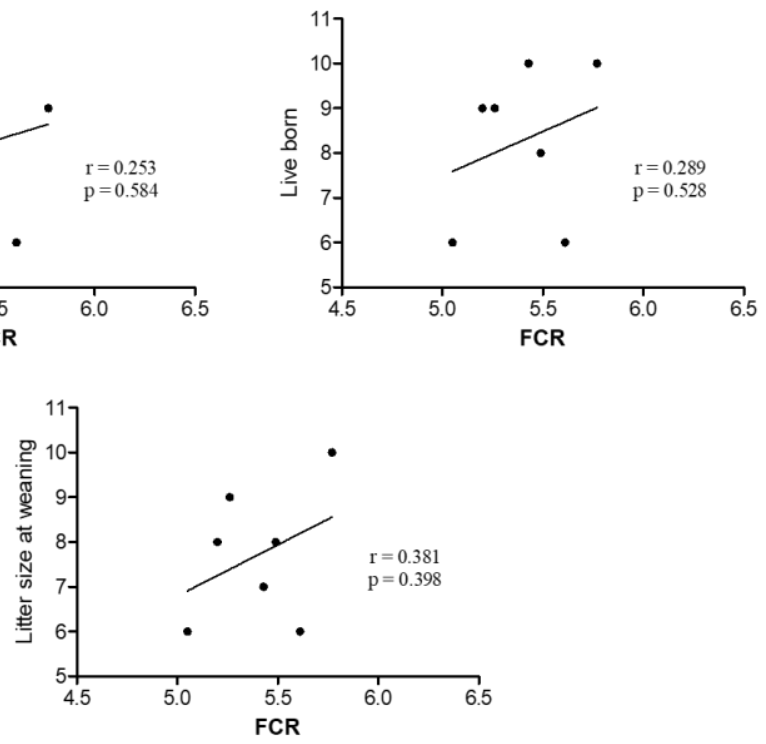

Statistics (2014). Ministry of Agriculture; Department of Animal Husbandry, Dairying and Fisheries, Krishi Bhawan.

Henry, Y., 1992. Influence of diet composition on feed efficiency and utilisation in growing-finishing pigs. World Rev. Anim. Prod. 27, 76 - 92.

Livestock Census 2012. $19^{\text {th }}$ Livestock census.

Department of Animal husbandry,

Dairying and Fisheries, Ministry of Agriculture, GOI, New Delhi.

Lopez, J., G.W. Jesse, Becker, B.A. and Ellersieck, M.R. 1991. Effects of temperature in the performance of finishing swine: II. Effects of a cold, diurnal temperature on average daily gain, feed intake, and feed efficiency. J. Anim. Sci. 69, 1850-1855.

Muirhead, M.R., 1989. Factors affecting efficient growth rate in the feeding pig. Vet. Ann. 29, 103-109.

Straw, B.E., V.K. Tuovinen and BigrasPoulin, M. 1989. Estimation of the cost of pneumonia in swine herds. J. Am. Vet. Med. Assoc. 195, 1702-1706. 
Tribble, L. F., W. H. Pfander, F. Lasley, S. E. Zobrisky and Brady, D. E. 1956. Factors Affecting Growth, Feed
Efficiency and Carcass in Swine. Missouri Agricultural Experiment Station Research Bulletin 609.

\section{How to cite this article:}

Kandarpa Boruah, Jitendra Saharia, Simson Soren, Karuna Saikia, Arindam Chakraborty and Mridusmrita Burhagohain. 2018. Feed Conversion Efficiency (FCE) in Relation to Reproductive Performance of Sow. Int.J.Curr.Microbiol.App.Sci. 7(01): 2915-2919. doi: https://doi.org/10.20546/ijcmas.2018.701.348 